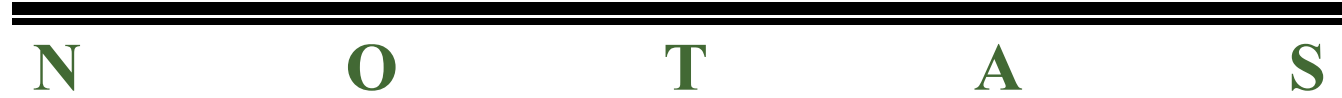




\section{SOBRE «DEFINICIONES Y NORMAS»}

\section{Introducción}

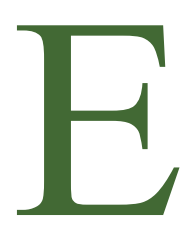

s bien sabido que en El concepto de Derecho Hart distingue entre reglas primarias y reglas secundarias. Pero, como ha sido puesto de manifiesto por diversos autores, esta distinción no es del todo clara ${ }^{1}$, pues Hart utiliza como si fueran intercambiables tres criterios de distinción que, sin embargo, producen resultados clasificatorios diferentes. Estos criterios son los siguientes: 1. reglas primarias son las que imponen deberes, reglas secundarias las que confieren poderes; 2. las reglas primarias regulan acciones que implican movimientos o cambios físicos, las secundarias prevén actos que conducen a cambios normativos; y 3. las reglas primarias se refieren a las acciones que los individuos deben hacer o no hacer, las secundarias se refieren a reglas del primer tipo. La falta de claridad de la distinción entre reglas primarias y secundarias proviene, pues, de que podemos encontrarnos con enunciados jurídicos concretos que, según un criterio, serán reglas primarias y, según otro, reglas secundarias. Ello, naturalmente, convierte en inconsistente dicha clasificación. ${ }^{2}$

Ahora bien, si nos situamos en el contexto de una teoría de la individualización de disposiciones jurídicas, parece que -siguiendo a Raz- podemos convenir que la distinción más relevante es la que opone las reglas que imponen deberes a las reglas que confieren poderes. En Hart, sin embargo, esta distinción agota el campo de las disposiciones jurídicas susceptibles de ser

${ }^{1}$ Para una exposición completa de la crítica a la distinción hartiana entre reglas primarias y reglas secundarias, puede verse el libro, pendiente de publicación por el CEC, de Juan Ruiz Manero, Jurisdicción y normas. Dos estudios sobre función jurisdiccional y teoría del Derecho (en el original, págs. 118 y sigs.).

${ }^{2}$ Ibidem, págs. 118 y sigs. 
individualizadas; es decir, para este autor toda disposición jurídica es o bien una regla que impone deberes o bien una regla que confiere poderes $^{3}$. En este sentido, podría decirse, tal vez, que en Hart la nota de la normatividad predicada del ordenamiento jurídico excluye la toma en consideración de disposiciones que no sean reglas o normas. Pues bien, en este trabajo me propongo confrontar esta dicotomía hartiana con una propuesta de Alchourrón y Bulygin $^{4}$ que consiste en considerar, por un lado, a las definiciones legales como enunciados jurídicos diferentes de las normas (de conducta) y, por otro, a las reglas que confieren poderes no como normas sino como definiciones o reglas conceptuales. Finalmente, trataré de mostrar que una teoría de la individualización de disposiciones jurídicas debe operar como mínimo con tres categorías: reglas o normas que imponen deberes, reglas o normas que confieren poderes y definiciones ${ }^{5}$.

\section{Definiciones y normas}

Carlos E. Alchourrón y Eugenio Bulygin, en un trabajo de 1983 titulado «Definiciones y normas», han tratado de formular una crítica contra la que ellos denominan «tesis normativista». Esta tesis se caracterizaría por sostener que el Derecho «está compuesto exclusivamente por normas y que, por lo tanto, to-

${ }^{3}$ Joseph Raz, El concepto de sistema jurídico (trad. de Rolando Tamayo y Salmorán), Ed. UNAM, México, 1986, pág. 199.

${ }^{4}$ Carlos E. Alchourrón y Eugenio Bulygin, «Definiciones y normas», en Eugenio Bulygin, Martín D. Farrel, Carlos S. Nino y Eduardo Rabossi (comps.): El lenguaje del Derecho. Homenaje a Genaro R. Carrió, Ed. Abeledo-Perrot, Buenos Aires, 1983, págs. 12 y sigs.

${ }^{5}$ Subrayo el «como mínimo» porque soy consciente de que una buena teoría de la individualización de disposiciones jurídicas probablemente deba tomar en consideración otras categorías además de las aquí contempladas. Piénsese, por ejemplo, en la necesidad de introducir criterios que permitan individualizar principios. En este sentido, y aunque aquí no voy a ocuparme de ellos, no está de más apuntar dos ideas en relación con la distinción entre reglas y principios: 1 . La discusión suscitada en torno a esta distinción afecta exclusivamente a las reglas que imponen deberes y nunca a las reglas que confieren poderes; entre principios y reglas que confieren poderes no se produce penumbra conceptual. 2. La principal diferencia entre reglas que imponen deberes y principios radica en que mientras que las reglas son mandatos que imponen una determinada medida de cumplimiento, los principios son mandatos de optimización, esto es, imponen el cumplimiento de un deber en la mayor medida posible en relación con las posibilidades fácticas y jurídicas. Cfr. Alexy, Robert: «Sistema jurídico, principios jurídicos y razón práctica», en Doxa. Cuadernos de Filosofía del Derecho, núm. 5, 1988, págs. 143 y sigs. 
dos los artículos de un texto legislativo son normas ya que su función es la de prescribir conductas, aunque pueden no ser normas jurídicamente completas $\rangle^{6}$. Pero -continúan Alchourrón y Bulygin-, es notorio que en muchos casos los artículos de un código definen el significado de un término y, si ello es así, habrá que preguntarse a quién y a qué obliga una definición formulada por el legislador. La respuesta que da la tesis normativista a esta cuestión es que las definiciones del legislador obligan a todos los que usan y aplican las normas jurídicas a utilizar las referidas definiciones; en otras palabras, obligan a entender (y a usar) las expresiones definidas en (con) el sentido que el legislador les ha atribuido ${ }^{7}$. Frente a esta tesis, Alchourrón y Bulygin sostienen la idea de que la función de las definiciones legales no es otra que la de contribuir a (y facilitar) la identificación de normas y en ningún caso la de prescribir conductas.

Para ello, distinguen entre lo que es el enunciado que expresa una norma y la norma misma. Así, si la norma es el sentido del enunciado que la expresa y si el sentido del enunciado depende del uso que se dé a las palabras que lo componen, entonces la definición legal lo que hace es simplemente facilitar la identificación de la norma expresada por el enunciado. En definitiva, lo que estos autores sostienen es que no hay diferencias entre una definición legal y una definición privada (esto es, no oficial): ambas cumplen la función de facilitar la identificación del sentido del enunciado en el que se contienen las palabras definidas ${ }^{8}$. Naturalmente, la afirmación de que las definiciones legales no son normas no quiere decir que su presencia en el interior de un sistema jurídico carezca de consecuencias normativas. En este sentido, Alchourrón y Bulygin advierten que si lo único que pretende la tesis normativista es afirmar la idea de que las definiciones legales tienen consecuencias normativas, entonces habrá que concluir -dicen- que las discrepancias entre ellos y los autores que sostienen dicha tesis son meramente verbales.

Ahora bien, aunque es cierto que normas y definiciones juegan papeles muy distintos, también lo es que en multitud de ocasiones existen grandes dificultades para diferenciarlas, pues ambas presentan semejanzas que resultan muy sugestivas: la principal consiste en que tanto las definiciones como las normas son el resultado de una decisión y, por ello, ni unas ni otras

\footnotetext{
${ }^{6}$ Carlos E. Alchourrón y Eugenio Bulygin, op cit., pág. 12.

${ }^{7}$ Cfr. ibidem, pág. 13.

${ }^{8}$ Cfr. Ibidem, pág. 26.
} 
pueden ser calificadas como verdaderas o falsas. Sin embargo, Alchourrón y Bulygin proponen dos vías para diferenciarlas: a) La primera consiste en recurrir a la distinción entre uso y mención de las palabras, y así afirman que cualquiera que sea la forma efectiva en que el legislador ha formulado una definición, ésta siempre es traducible a lo que ellos denominan la «forma canónica de definir» ${ }^{9}$. b) La segunda vía consiste en percatarse de que «si las normas han de cumplir una función prescriptiva, la de guiar las conductas, es esencial que sea posible cumplirlas y que sea también posible no cumplirlas [...] En este sentido las normas son sintéticas y las situaciones que ellas exigen han de ser siempre contingentes, ya que no pueden ser ni necesarias ni imposibles. En cambio, las definiciones crean siempre una imposibilidad; si la demanda se define como un documento escrito, es imposible que una demanda sea oral [...] De esta manera una definición da lugar a enunciados necesarios, cuya necesidad está basada en el significado del término definido, es decir, se trata de enunciados analíticos. Es por eso que las definiciones que asignan un significado a un término (definiciones estipulativas), si bien ellas mismas no pueden ser calificadas de analíticas, dan lugar a enunciados analíticos, es decir, enunciados que se justifican con el mero significado de los términos que aparecen en ellos» ${ }^{10}$. Ahora bien, «la línea divisoria entre enunciados analíticos y definiciones por un lado y las normas por el otro es, hasta cierto punto, arbitraria, pues no existe un criterio que permita decidir en todos los casos frente a un artículo determinado si éste expresa un enunciado analítico (o una definición) o una norma. Sólo la reconstrucción global de un texto completo permitirá identificar ciertos artículos como definiciones o enunciados analíticos y otros como formulaciones de normas. Pero al mismo tiempo surge que siempre ha de haber tanto normas, como definiciones y enunciados analíticos, aunque las definiciones pueden no estar formuladas explícitamente ${ }^{11}$.

Finalmente, estos autores recurren a las nociones de «sanción»y «nulidad» para sostener la tesis de que el ordenamiento jurídico está compuesto por normas de conducta y definiciones (o reglas conceptuales). En este sentido, en parte recurriendo a Hart y en parte criticándolo, Alchourrón y Bulygin escriben:

${ }^{9}$ La forma canónica se puede representar de la siguiente manera: «...» significa...; donde «...» representa a la expresión mencionada (definiendum) y... las palabras que se usan para indicar su sentido (definiens), Cfr. ibidem, pág. 31.

${ }^{10}$ Ibidem, pág. 34.

${ }^{11}$ Ibidem, pág. 38. 
«Así como las sanciones (castigos, penas) constituyen la forma típica de reaccionar frente al incumplimiento de obligaciones (o transgresión de prohibiciones, que es lo mismo), la nulidad (en sus diversos matices [...]) constituye una reacción típica frente a objetos (actos, documentos, normas) que no reúnen los requisitos exigidos por una definición, con la diferencia de que -como muestra Hart- la nulidad es inseparable de la definición, mientras que una norma de obligación puede existir aunque no esté acompañada por una sanción» ${ }^{12}$.

\section{Definiciones y reglas que confieren poderes}

De todo lo dicho hasta aquí creo que puede extraerse la conclusión de que existen buenos argumentos para sostener que una teoría de la individualización de disposiciones jurídicas debe incluir criterios que permitan individualizar definiciones ${ }^{13}$. Ahora bien, si lo anterior es cierto, también lo es -creo- que probablemente Alchourrón y Bulyg1n llevan demasiado lejos sus argumentos, pues según ellos el Derecho estaría compuesto por normas de conducta (normas que imponen deberes) y definiciones (o reglas conceptuales). En lo que sigue voy a tratar de mostrar la oportunidad de mantener la distinción (desdibujada por Alchourrón y Bulygin) entre reglas que confieren poderes y definiciones ${ }^{14}$.

\footnotetext{
${ }^{12}$ Ibidem, pág. 41.
}

${ }^{13}$ Victoria Iturralde Sesma ha estudiado -en Lenguaje legal y sistema jurídico, Ed. Tecnos, Madrid, 1989- diversas cuestiones relacionadas con las definiciones legales. En un momento de su exposición aborda el problema del carácter vinculante o no de las mismas para el intérprete. Así, tras exponer algunos de los argumentos en favor y en contra que se han formulado en la tradición jurídica, concluye afirmando que «el intérprete está sujeto a ellas en la misma medida en que lo está respecto de cualquier otro enunciado normativo y que, en el momento interpretativo-aplicativo de la ley, no puede hacer abstracción de lo que en ellas se disponga» (pág. 60). En este punto, tan sólo quiero llamar la atención sobre el hecho de que esa conclusión no incide para nada en la discusión que ocupa a Alchourrón y Bulygin, puesto que no hay inconveniente en afirmar simultáneamente que la función de las definiciones legales no es la de prescribir conductas, sino la de contribuir a la identificación de normas, por un lado, y, por otro, que hay operadores jurídicos que tienen la obligación de aplicar (y, por tanto, de identificar) el Derecho. En otras palabras, como decían Alchourrón y Bulygin, una cosa es sostener que las definiciones legales no son normas y otra muy distinta es que su presencia en el interior de un sistema jurídico carezca de consecuencias normativas.

${ }^{14}$ Gregorio Robles ha elaborado una tipología de reglas jurídicas. En ella distingue entre «reglas ónticas» (que son las que crean los elementos necesarios 
Como se ha visto, Alchourrón y Bulygin sostienen que todas las definiciones son traducibles a una forma canónica y que no hay diferencias entre las definiciones que realiza el legislador y las definiciones estipulativas privadas. Además, estos autores vinculan la nulidad con las definiciones o reglas conceptuales. Ahora bien, no todo aquello que puede ser definido por el legislador con consecuencias normativas se encuentra conectado con la noción de nulidad. Por ello, resulta conveniente profundizar en el análisis, pues no parece que sea lo mismo definir un término no jurídico, como «ordenador», que definir un término técnico-jurídico ${ }^{15}$; y, a su vez, dentro de estos últimos, probablemente haya alguna diferencia entre definir, por ejemplo, «bien mueble» o «heredero» (de los que no tiene sentido predicar la nulidad o la validez) y «testamento» (del que sí se puede predicar la nulidad o la validez $)^{16}$.

de carácter estático del sistema, esto es, el espacio, el tiempo, los sujetos y las competencias), «reglas técnico-convencionales o procedimentales» (que son las que crean el elemento necesario de carácter dinámico, esto es, el procedimiento) y las reglas deónticas o normas (que son las que expresan un deber). Lo fundamental, sin embargo, en este punto es mostrar cómo el lugar que Robles asigna a las definiciones legales dentro de su esquema lo aproxima mucho a la tesis normativista. Así, escribe en el apartado relativo a las reglas deónticas: «[...] no hay propiamente preceptos que sean definiciones, si por tal entendemos la descripción de algo dado de antemano [...] Hay reglas ónticas que establecen elementos necesarios del sistema, y hay preceptos que establecen autoritariamente el sentido de una palabra o expresión. Sobre la base de unas y otras, el intérprete puede definir alcanzando así las definiciones legales. Estas no se sitúan, pues en el marco del discurso del legislador, el cual sólo ordena, sino en el del intérprete.» En G. Robles, Las reglas del Derecho y las reglas de los juegos, Ed. Universidad de Palma de Mallorca, 1984, pág. 223.

${ }^{15}$ Martino clasifica las definiciones legales según el tipo de término definido; así distingue entre términos técnico-jurídicos y términos no-técnico jurídicos. En este sentido, escribe: «se dirá de una definición legislativa que define un término técnico-jurídico, si el definiendum pertenece a la teoría jurídica, y en dicha teoría permite que se le apliquen relaciones específicas (leyes) que lo ligan a otros términos técnicos (algunos de los cuales están presentes en su definiens), y se usa para aquel fin primario»; y a ello añade que estas definiciones tienen un carácter fundamentalmente constitutivo. Ahora bien, el propio Martino advierte sobre la influencia recíproca que existe entre el lenguaje ordinario y el lenguaje técnico-jurídico. Cfr. Antonio A. Martino, Le definizioni legislative, Ed. Giappichelli, Torino, 1975, págs. 42 y sigs., y 85 y sigs.

${ }^{16}$ Para una tipología de los términos que componen el léxico del lenguaje de los documentos jurídicos puede verse Josep Aguiló Regla, «Lenguaje jurídico, lenguaje documental y tesauro», en Theoria, núm. 12-13, 1990, págs. 31 y sigs. En dicho trabajo la tipología de términos se realiza en función de las relaciones que cada término mantiene con el léxico del lenguaje natural y, a partir de ahí, se estudia la relevancia de cada grupo de términos a la hora de construir un tesauro jurídico. 
En efecto, si tomamos términos como «ordenador», «bien mueble», «homicidio», «heredero», «menor de edad», etc., y tra tamos de analizar las definiciones de los mismos contenidas en nuestros textos legales, observamos que, realmente, es difícil sostener que estas definiciones cumplen alguna función diferente a la que desempeña cualquier definición estipulativa en el interior de un determinado texto. Algunas de ellas podrían ser criticadas, pero lo fundamental radica en que todas tratan de especificar el significado de términos incluidos en enunciados que expresan normas jurídicas; y, en este sentido, cumplen la función de ayudar a identificar las normas expresadas por esos enunciados. Los términos arriba enumerados aluden a clases de objetos, de sujetos o de acciones y sus definiciones tratan de eliminar ambigüedades y vaguedades. Algunas de estas definiciones amplían y otras restringen o precisan el significado que las palabras definidas tienen en el uso común del lenguaje natural. En este sentido, todas ellas son redefiniciones. En relación con estas definiciones, al igual que ocurre con las privadas, las cuestiones que se suscitan giran en torno a la pertenencia o no a determinadas clases: por ejemplo, si un sujeto es o no heredero, si una acción es o no homicidio o (ejemplo de definición privada) si una determinada persona es o no conservadora. Y, finalmente, y es lo más importante, de ninguna de esas palabras (ni de los objetos, sujetos o acciones por ellas denotados) tiene sentido predicar la validez o la nulidad.

Frente a este tipo de definiciones, en el Derecho nos encontramos también con enunciados que parecen definiciones, pero que en realidad hacen algo más que especificar el sentido en el que se usa un término. Ese «algo más» consiste en que de algún modo esos enunciados especifican las condiciones de validez o nulidad de algo. Como puede verse, aquí vamos a utilizar los predicados «validez»y «nulidad» como indicio de una distinción importante ${ }^{17}$. Por ello, en este punto, conviene formularse la si-

${ }^{17}$ Hernández Marín sostiene -en El derecho como dogma, Ed. Tecnos, Madrid, 1984- que en el Derecho no sólo hay normas de obligación (prescripciones) sino también disposiciones cualificatorias (que no son normas). Define a estas últimas del siguiente modo: «son oraciones que atribuyen una propiedad a, o incluyen en una determinada clase, todas las entidades que tengan una determinada propiedad, o que pertenezcan a una cierta clase» (págs. 30 y 31). En un punto del libro, el autor se pregunta si la distinción entre normas y disposiciones cualificatorias coincide con la formulada por Hart entre reglas primarias y reglas secundarias, a lo que responde que, dada la imprecisión de esta última distinción es difícil dar una respuesta segura (pág. 41). En cualquier caso, en mi opinión, entre ambos autores hay una diferencia de fondo a propósito 
guiente pregunta: ¿de qué puede predicarse la validez o la nulidad? Si yo no me equivoco, la validez o la nulidad sólo pueden predicarse con sentido de los actos creadores de normas (o de las normas creadas por esos actos) y de los actos aplicadores de normas (o del contenido de las decisiones tomadas en esos actos). Y tanto los actos creadores de normas como los aplicadores de normas son los típicos actos regulados por las reglas que confieren poderes. Si ello es así, conviene ahora preguntarse cuáles son los elementos básicos de toda regla que confiere poderes. En mi opinión, y aunque lo que voy a decir requeriría mayor elaboración, dentro de las reglas que confieren poderes pueden distinguirse los tres elementos siguientes: a) la determinación de un sujeto normativo, esto es, una persona, clase de personas o un cuerpo de personas a los que se les confiere el poder; $b$ ) la definición del acto o de la clase de actos que el hecho de ser titular del poder en cuestión permite realizar; dentro de esta definición (que sin duda es constitutiva) se contienen los requisitos procesales (o formales) y materiales que el acto debe reunir para que pueda ser considerado como un acto jurídico creador o aplicador de normas. En otras palabras, en la definición se contienen las condiciones de validez (y, por tanto, también las de nulidad) del acto en cuestión; y c) la determinación de los efectos jurídicos que tiene el acto válidamente realizado. Si faltase alguno de estos tres elementos difícilmente podríamos decir que estamos ante una regla que confiere poderes: sin sujeto normativo no hay regla posible; la nulidad -como ha puesto de manifiesto Hart- es inseparable de las reglas que confieren poder; y la realización de actos que carecen de efectos no tiene mucho sentido.

Ahora bien, a la vista de lo que proponían Alchourrón y Bulygin, ¿es preferible concebir a estas disposiciones como «reglas que confieren poderes» o como «definiciones» (o reglas conceptuales)? En mi opinión, concebirlas como definiciones plantea al menos el siguiente problema: si concebimos a estas disposiciones como definiciones, entonces la afirmación de Alchourrón y Bulygin de que no hay diferencia entre una definición legal y una definición privada se convierte en insostenible, pues no tiene sentido decir que la nulidad (o la validez) es inse-

de la idea de normatividad. Sin embargo, en este punto del trabajo y con independencia de la respuesta que pueda darse a la pregunta anterior, lo que interesa es llamar la atención sobre la circunstancia de que para Hernández Marín son disposiciones cualificatorias tanto las llamadas normas de competencia «que califican ciertas cosas como válidas» (pág. 40), como, por ejemplo, la definición legal de «bien inmueble» (pág. 85). 
parable de cualquier definición estipulativa. Muy al contrario, el concepto de validez (en el sentido en que aquí se utiliza) sólo es relevante en contextos normativos y, en particular, en contextos creadores o aplicadores de normas. Ahora bien, ello nos autoriza sólo a diferenciar estas disposiciones de las definiciones antes estudiadas, pero no nos permite calificarlas de reglas. En mi opinión, el test que toda disposición debe superar para que pueda ser calificada de regla (o norma) es la de comprobar si efectivamente cumple la función de motivar las conductas ${ }^{18}$.

Dentro de la teoría del Derecho se ha intentado en diversas ocasiones asimilar la nulidad a la sanción con el fin de mostrar que el Derecho guía la conducta de los individuos de un único modo. Las críticas que se han formulado a estos intentos son conocidas y creo que incontestables. Sin embargo, es cierto también que las nociones de validez y nulidad han sido estudiadas sobre todo desde perspectivas estructurales y que para mostrar cómo guían la conducta las normas que confieren poderes tal vez sea imprescindible analizar estas nociones desde perspectivas funcionales. Aquí no voy a afrontar el referido análisis funcional, pues excede con mucho las pretensiones de este trabajo, sino que tan sólo pretendo apuntar algunas de las hipótesis que, creo, este análisis debería tratar de confirmar: 1) la validez puede ser considerada como una sanción positiva, pues al final se traduce siempre en un respaldo coactivo que el Derecho ofrece al titular del poder. Ello me parece particularmente claro en los casos en que la facultad conferida es privada y su ejercicio es facultativo. 2) La nulidad, si bien no puede ser considerada -como ya se ha dicho- como una sanción negativa, sí puede ser vista como la negación o la ausencia de una sanción positiva, pues la nulidad al final se traduce siempre en una «negativa a prestar la coacción estatal» ${ }^{19}$. 3) En los casos en los que el ejercicio del poder conferido es facultativo no es cierto que el Derecho sea neutral en el sentido de que no defina ninguna conducta como deseada ${ }^{20}$, pues no hay que olvidar que el Derecho tiene un interés en lo que se

${ }^{18} \mathrm{Raz}$-al mostrar cómo inciden las reglas que confieren poderes en el razonamiento prácticoprobablemente sea el autor que mejor ha expuesto la forma en que estas reglas cumplen la función de guiar las conductas. En este sentido, puede verse, por ejemplo, Raz, Joseph: «Postcriptum», en $E l$ concepto de sistema jurídico, op. cit., págs. 272 y sigs.

${ }^{19}$ Carlos S. Nino, «La nulidad jurídica y el papel de la Teoría general de Derecho», en el libro del mismo autor La validez del Derecho, Ed. Astrea, Buenos Aires, 1985, pág. 203.

${ }^{20}$ Téngase en cuenta que si no se define una conducta como deseada no tiene sentido hablar de sanción positiva. 
suele llamar «seguridad en el tráfico». En efecto, si bien el Derecho es perfectamente neutral, por ejemplo, frente al hecho de que alguien haga o no haga testamento, no lo es ya ante el hecho de que aquél que quiera fijar el destino de sus bienes para después de su muerte lo haga de cualquier manera. El Derecho reconoce una manera y a ésa es a la que le presta respaldo coactivo: la acción de dictar testamento válido es una conducta deseada por el ordenamiento jurídico y por tanto premiada, pero no deseada y premiada frente a la de no dictar testamento, sino deseada y premiada frente a la de dictar testamento no válido. En definitiva, en estos casos, y como siempre se dijo, el Derecho motiva los medios no los fines. 